\title{
Trends in the consumption rates of benzodiazepines and benzodiazepine- related drugs in the health region of Lleida from 2002 to 2015
}

\author{
F. Torres-Bondia ${ }^{1 \dagger}$, J. de Batlle $2,3+$, L. Galván ${ }^{4}$, M. Buti ${ }^{5}$, F. Barbé 2,3 and G. Piñol-Ripoll ${ }^{6^{*}}$
}

\begin{abstract}
Background: The high prevalence and long-term use of benzodiazepines (BZDs) treatment are debated topics because of the risk they can cause to the patients. Despite the current information on the risk-benefit balance of these drugs, their consumption remains particularly high. We determined the trend in the consumption prevalence of benzodiazepines (BZDs) and drugs related to BZDs (Z-drugs) in the population of the Health Region of Lleida to explore patterns of use and the associated characteristics associated between 2002 and 2015.

Methods: An analysis of secular trends was carried out between 2002 and 2015; the databased included all individuals from the Health Region of Lleida, which had 358,157 inhabitants in 2015, that consumed BZDs. The consumption of BZDs was evaluated using prescription billing data from the Public Health System. All types of BZDs and BZD analogues that had been approved by the drug agency were included. Trends by age and sex were investigated.

Results: Over the whole study period, a total of 161,125 individuals accounted for 338,148 dispensations. Overall, 59\% were women, and the mean age was 56 years. The dispensing prevalence of BZDs use in 2015 was 14.2\% overall $-18.8 \%$ in women and $9.6 \%$ in men-and was $36 \%$ in those over 65 years. According to the half-life of BZDs, the prevalence of short-intermediate BZD use, intermediate-long BZD use, and Z-drugs use was 9.7, 5.5 and $0.8 \%$, respectively. The evolution of the annual prevalence of BZD dispensing showed a progressive decline, from $15.3 \%$ in 2002 to $14.2 \%$ in 2015, which was attributed to a decrease in the consumption of intermediate-long halflife BZDs (8.0\% vs. $5.5 \%$ ) and Z-drugs (1.4\% vs. 0.8\%).

Conclusion: The dispensing prevalence of BZDs and Z-drugs was high, although a small reduction was observed during this time period. The dispensing prevalence was especially high in the population over 65 , despite the risk of cognitive decline and falls. Integral actions are required to lower the BZD prescription rate.
\end{abstract}

Keywords: Benzodiazepines, Sedative-hypnotics, Prescribing trends, Drug safety, Drug utilization

\footnotetext{
* Correspondence: gerard_437302@hotmail.com

${ }^{\dagger} \mathrm{F}$ Torres-Bondia and J de Batlle are co-first authors and contributed equally to this study.

${ }^{6}$ Unitat Trastorns Cognitius (Cognitive Disorders Unit), Clinical Neuroscience Research, IRBLleida, Santa Maria University Hospital, Rovira Roure n 44, 25198 Lleida, Spain

Full list of author information is available at the end of the article
}

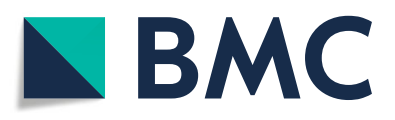

(- The Author(s). 2020 Open Access This article is licensed under a Creative Commons Attribution 4.0 International License, which permits use, sharing, adaptation, distribution and reproduction in any medium or format, as long as you give appropriate credit to the original author(s) and the source, provide a link to the Creative Commons licence, and indicate if changes were made. The images or other third party material in this article are included in the article's Creative Commons licence, unless indicated otherwise in a credit line to the material. If material is not included in the article's Creative Commons licence and your intended use is not permitted by statutory regulation or exceeds the permitted use, you will need to obtain permission directly from the copyright holder. To view a copy of this licence, visit http://creativecommons.org/licenses/by/4.0/. The Creative Commons Public Domain Dedication waiver (http://creativecommons.org/publicdomain/zero/1.0/) applies to the data made available in this article, unless otherwise stated in a credit line to the data. 


\section{Background}

Benzodiazepines (BZDs) and drugs related to benzodiazepines (Z-drugs) are one of the most highly used pharmacological groups globally, especially in developed countries [1, 2]. Their consumption has reached $30 \%$ for people over 65 years of age in France [3], more than 20\% in Canada [4] and Spain [5], 15\% in Australia [6], and between 9 and $12 \%$ in the US [7, 8].

These drugs are mainly indicated for the treatment of generalized anxiety disorder and insomnia, although they are also indicated for panic attacks, phobic disorders, obsessive-compulsive disorders, post-traumatic stress, epilepsy, and muscle spasms [9]. In adults older than 65 years, good practice guidelines do not recommend their use in the treatment of insomnia, agitation, or delirium and it is recommended that BZD use, if any, be shortterm [10]. Thus, a maximum duration of between 2 and 4 weeks for insomnia or anxiety and no more than 2 weeks for mixed anxiety-depressive disorders are advised [11]. These recommendations were based on the longterm development of tolerance, dependence, abuse and withdrawal syndrome [12], although recent retrospective studies showed a level of dependence after chronic consumption that was lower than previously described, even in older people [13]. In any case, BZDs have been demonstrated to increase the risk of falls, hip fractures and detrimental cognitive effects $[14,15]$.

Despite these recommendations, the use of BDZs is a cause for concern in the public health systems of different countries due to their high prescription prevalence and the risks associated with long-term exposure [16].

Most BZDs are prescribed by primary care services due to the greater number of elderly patients who visit these practices [7]. However, in relative terms, psychiatrists present the highest prescription rates [17]. According to previous studies, only $20-30 \%$ of prescription of BZDs prescriptions are appropriate [18, 19]; in Canada, this means an extra cost of CAN $\$ 3076$ per person per year in hospitalization, emergency department and outpatient costs [20]. In older people, two aspects as hospitalization and nursing home admission, are triggers for the initiation of BZDs; between 13 and 69\% of hospitalized older people use BZDs [21, 22], and the prevalence of BZD use in nursing home residents is $25-50 \%$ [23-25].

The chronic use of BZDs has a great impact on the elderly beyond the risk of dementia, traffic accidents or falls. Thus, other aspects such as a fear of falling, tripping, almost falling, loneliness, social isolation, depression or reduced of social participation can be side effects of treatment with BZDs [26]. Thus, people with a higher risk of falls have lower functional activity and social participation, which can lead to a higher risk of depression and anxiety, an increased use of BZD and, subsequently, more falls [27]. All these aspects also have economic and social consequences; thus, the estimated additional costs of the falls associated with BZD in the European Union were 1800 million euros per year [28].

The general objective of this study was to determine the dispensing prevalence and characteristics of BZD and Z-Drug consumption in a Spanish cohort over a period of 14 years. The specific objectives were to explore the dispensing prevalence of BZD use, the types of BZDs (short-intermediate half-life or intermediate-long half-life) and Z-drugs prescribed, the age and sex characteristics associated with long-term consumption, and the use trends during this time period.

\section{Materials and methods}

This was an analyses of secular trends carried out between January 1, 2002 and December 31, 2015. The database consisted of all individuals of any age and sex who were assigned, either by a doctor or by the Basic Health Area (the Basic Health Area corresponds to the territory and its population, which is attended by a Primary Care Team, whose basic nucleus is made up of professionals from Family Medicine, Paediatrics, Nursing and administrative support staff), to the Health Region of Lleida (Catalonia), with had a catchment area of 358, 157 inhabitants in 2015.

To assess the consumption of BZDs and Z-drugs, pharmacy dispensing information from the Public Health System was used; this information contains the number of packages dispensed in the pharmaceutical offices under their charge. Spain has a public health system where the drugs are dispensed in pharmaceutical offices after showing a prescription by a doctor (usually prescribed by a general practitioner or sometimes by specialist in ambulatory patients). This study contains dispensing information from pharmaceutical offices; the following assumptions: consumption associated with mutual insurance entities or other insurers, drugs administered to hospitalized patients, drugs prescribed by private providers who dispensed drugs without a prescription were excluded. In Spain, these combined avenues represented less than $2 \%$ of drug consumption.

The best source of data for studies to evaluate the prescription and consumption of drugs, are pharmacy dispensing records because they are based on actual purchases of drugs. Both the external and internal validity of these studies are high. Therefore, the current dispensing records make it possible to carry out a highly reliable analysis at the individual level of drug consumption $[29,30]$.

It has been observed that patients who consume BZDs continue their prescriptions over time, and the data suggest that BZD use is more likely to be underestimated than overestimated [31]. It can be assumed, therefore, 
that the purchased treatments were in fact consumed [31]. Therefore, the use of this source of information allowed a good approximation of actual consumption; however, depending on the prevalence of acute or occasional uses, an overestimation is possible when using dispensing data. Anxiolytic and hypnotic BZDs were defined following the anatomical therapeutic classification (ATC) of the World Health Organization (WHO) [32]: N05BA (anxiolytics, BZD derivatives), N05CD (hypnotics and sedatives, BZD derivatives), and N05CF (hypnotics and sedatives, benzodiazepine-related drugs, also called Z-drugs).

All BZDs and Z-drugs in the aforementioned groups, which were approved in the drug catalogue of the Spanish Agency for Medications [33], were included during the study period. Zaleplon was excluded because it was not marketed in Spain during the study period.

The consumption of specialized pharmaceuticals was expressed as the defined daily dose (DDD). The DDD is a technical unit of measurement that corresponds to the daily maintenance dose of a drug for its main indication in adults and for a given route of administration. The DDDs of active ingredients are established by the WHO and are published on the WHO Collaborating Center for Drug Statistics Methodology website [32].

Long-term consumption over the whole study period was defined as a DDD $\geq 180$ DDD [34].

The following clinical and demographic variables were recorded: age; sex; type of Basic Health Area (classified as rural or urban) [35]; diagnoses (hypertension, diabetes mellitus, hyperlipidaemia, myocardial infarction, stroke, Alzheimer's disease or other dementia, anxiety, insomnia and depressive syndromes) according to the International Classification of Diseases, 10th revision (2018), Clinical Modification (ICD-10-CM) [36]; type of BZD, classified according to half-life, (short-intermediate or intermediate-long); and total number of BZDs.

A description of the study population was created based on absolute values and percentages or means and standard deviations. To calculate the percentages of the total population of the Health Region of Lleida, the official figures for that region were used. The dispensing prevalence of BZDs use was calculated by age, sex, and type of BZD (according to half-life) for individuals of any age who were charged for at least 1 prescription for any selected drug between January 1, 2002, and December 31, 2015. We considered global dispensing prevalence when we described the whole study period and annual dispensing prevalence when we described use over a given year.

This research project, with code P16/109, was approved by the reference ethics committee (Committee of Ethics and Clinical Research of Lleida - CEIC).

\section{Results}

During the period 2002-2015, the cohort of BZD and/or Z-drug consumers during the period 2002-2015 in the Health Region of Lleida consisted of 161,125 subjects. These individuals generated 338,148 records of dispensed treatments, which included all possible BZDs and Z-drugs. Table 1 shows the overall characteristics of the study population.

In the last year of follow-up (2015), the mean (SD) age was 56 (24) years. A total of $59 \%$ of the consumers were women, and $60 \%$ of the total cohort was assigned to the Basic Rural Area. In our study, the most frequent diagnoses associated with BZDs were anxiety $(24 \%)$ and depression (19\%), while insomnia accounted for only $2 \%$ of the recorded diagnoses. In this same year, 50,725 people were prescribed at least one BZD, representing an annual dispensing prevalence of $14.2 \%$, which was higher in women $(18.8 \%)$ than in men $(9.6 \%)$. This use increased with age, reaching $36.1 \%$ in people over 65 years of age (Table 2). According to the type of BZD (Table 2 ), the annual dispensing prevalence was $9.7 \%$ for the short-intermediate half-life BZDs and $5.5 \%$ for the

Table 1 Characteristics of the cohort of the study population between 2002 and 2015

\begin{tabular}{ll}
\hline & $\mathrm{n}(\%)$ \\
\hline Sex & \\
Women & $66,685(41 \%)$ \\
Age categories & $94,440(59 \%)$ \\
$<16$ & \\
$16-24$ & $1293(1 \%)$ \\
$25-44$ & $3676(2 \%)$ \\
$45-64$ & $36,165(23 \%)$ \\
$>64$ & $48,943(30 \%)$ \\
Setting: rural & $71,048(44 \%)$ \\
Main diagnoses & $96,145(60 \%)$ \\
Alzheimer's & \\
Dementia & $1172(0.7 \%)$ \\
Depression & $3710(2.3 \%)$ \\
Anxiety & $18,931(11.8 \%)$ \\
Sleep disorders & $37,933(23.5 \%)$ \\
Affective disorders & $3041(1.9 \%)$ \\
IC & $4159(2.6 \%)$ \\
HTA & $7228(4.5 \%)$ \\
Diabetes & $48,619(30.2 \%)$ \\
Dyslipidaemia & $19,774(12.27 \%)$ \\
Other & $38,976(24.2 \%)$ \\
\hline & $130,786(81.2 \%)$ \\
\hline Iscmis
\end{tabular}

IC Ischemic cardiomyopathy, HTA Hypertension 
Table 2 BZD and Z-drugs consumption dispensing prevalence in $2015(\%)$

\begin{tabular}{lllllll}
\hline & $<16$ & $16-24$ & $25-44$ & $45-64$ & $\geq 65$ & Total \\
\hline Men & & & & & & \\
Short-intermediate BZDs & 0.08 & 0.87 & 3.07 & 7.86 & 18.56 & 6.15 \\
Intermediate-long BZDs & 0.26 & 1.33 & 3.91 & 5.78 & 6.77 & 4.03 \\
Z-drugs & 0.01 & 0.06 & 0.17 & 0.70 & 1.60 & 0.50 \\
Total & 0.34 & 2.04 & 6.39 & 12.61 & 24.54 & 9.58 \\
Women & & & & & & \\
Short-intermediate BZDs & 0.08 & 1.81 & 5.84 & 15.57 & 35.79 & 13.38 \\
Intermediate-long BZDs & 0.28 & 2.47 & 5.64 & 10.27 & 11.74 & 6.97 \\
Z-drugs & 0.01 & 0.05 & 0.33 & 1.45 & 2.85 & 1.07 \\
Total & 0.34 & 3.93 & 10.32 & 23.35 & 45.08 & 18.84 \\
All & & & & & & \\
Short-intermediate BZDs & 0.08 & 1.32 & 4.38 & 11.55 & 28.28 & 9.73 \\
Intermediate-long BZDs & 0.27 & 1.88 & 4.73 & 7.93 & 9.57 & 5.48 \\
Z-drugs & 0.01 & 0.05 & 0.24 & 1.06 & 2.31 & 0.79 \\
Total & 0.34 & 2.95 & 8.25 & 17.76 & 36.13 & 14.16 \\
\hline
\end{tabular}

intermediate-long half-life BZDs. In the case of Z-drugs, the dispensing prevalence was $0.8 \%$.

Long-term consumption of BZDs (cumulative DDD $\geq 180$ ) was $10 \%$ in subjects between 25 and 44 years old, $22 \%$ in those between 45 and 64 years old, and $36 \%$ in those over 65 years old. Therefore, consumption was approximately 3 times more frequent in older people than in young adults. This long-term consumption was also associated with an increase in the prevalence of insomnia $(0.64 \%$ vs. $2.63 \%$; Pearson's chisquared $p$-value $<0.001)$ ).

If we consider the evolution of global dispensing prevalence during the study period, a slight decrease was observed, from $15.3 \%$ in 2002 to $14.2 \%$ in 2015 (Fig. 1). Regarding sex, during the study period, consumption in men decreased from 10.6 to $9.6 \%$ and in women from 19.6 to $18.8 \%$.

This decrease between 2002 and 2015 was attributed to a decrease in the consumption of BZDs with intermediate-long half-lives ( $8.0 \%$ vs. $5.5 \%)$, as well as a decrease in the consumption of Z-drugs ( $1.4 \%$ vs. $0.8 \%)$. However, there was an increase in the consumption of short-intermediate half-life BZDs ( $8.9 \%$ vs. 9.7\%), especially in women, who had an increase from 11.7 to $13.4 \%$, while it remained constant in men (6.1 vs. $6.1 \%)$ (Fig. 2).

When we considered the number of BZDs that the patients were taking, we found that in $2015,2.7 \%$ of the population consumed two or more BZDs, showing a progressive decrease from 2002, when the prevalence was $4.1 \%$ (Fig. 3). The most common BZDs used were lorazepam (36.3\%), diazepam (25.1\%), and lormetazepam (24.4\%).

\section{Discussion}

The results of the present study demonstrate a high prevalence in the prescription of BZDs and Z-drugs in a large population-based cohort throughout the observation period. Despite the insistence on the need to reduce the use of these drugs, there was only a slight decrease $(2.47 \%)$ in the consumption of long half-life BZDs during the 13 years follow-up period, while no differences in the consumption of short half-life BZDs or Z-drugs.

According to the prescription patterns observed in Europe [2, 37-44] and US [45], the use of BZDs in this region of Catalonia was greater in women, especially elderly women.

In primary care, insomnia (42\%) and anxiety (36\%) are the most common indications for new prescriptions of BZDs and justify the long-term use of BZDs [46]; however, in our study, anxiety was much more frequent (24\%) than insomnia (2\%).

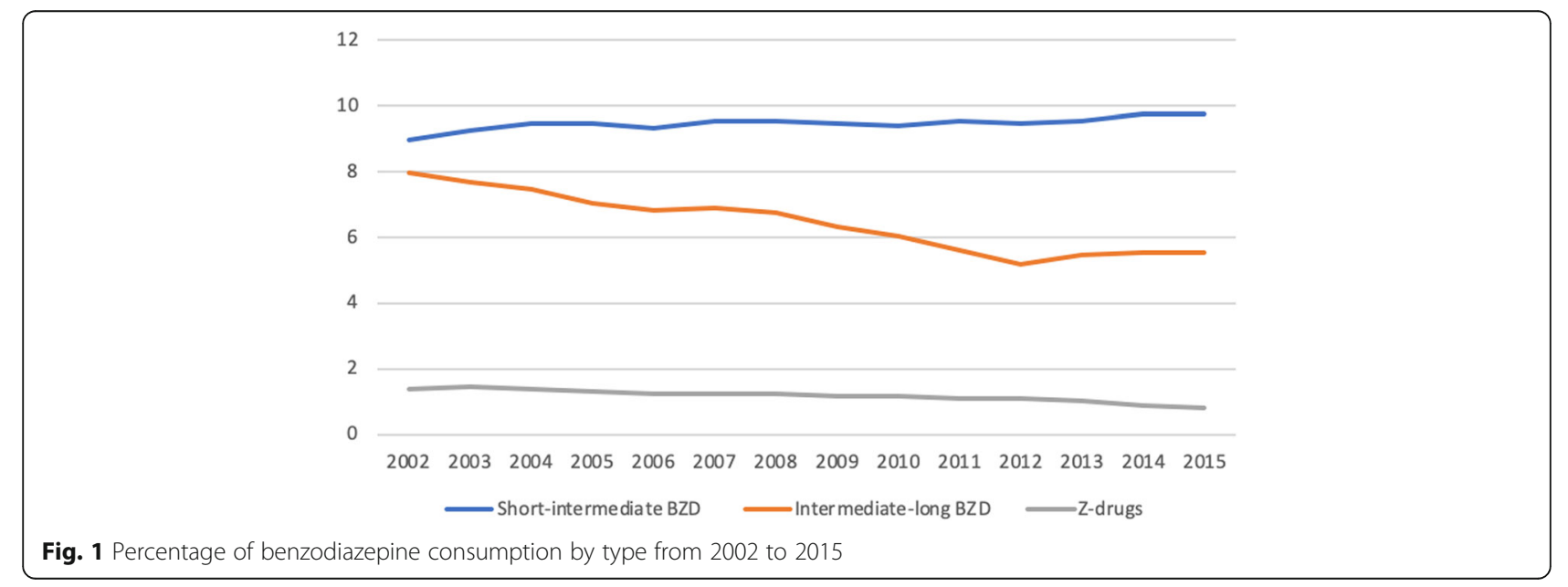




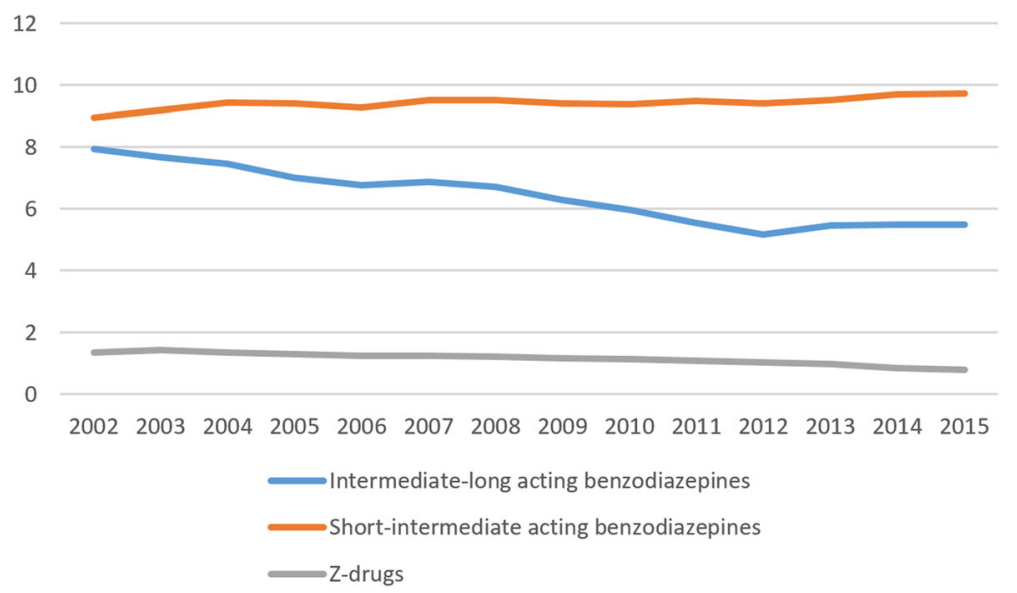

Fig. 2 Trends of percentage of short-intermediate, intermediate-long half-life benzodiazepine and Z-drug consumption by sex from 2002 to 2015

Clinical guidelines recommend that BZDs and other hypnotics should only be used in the short term in cases of severe insomnia and should only be initiated after considering non-pharmacological measures, such as sleep hygiene, stimulus control and relaxation measures [47]. However, in line with the high rates of BZD use in elderly patients, a qualitative analysis of in-depth interviews with primary care physicians from Philadephia revealed that most prescribers did not consider the continued use of BZDs in older adults to be a public health problem [48] and perceived that these drugs were more effective than non-pharmacological approaches for insomnia $[49,50]$. No similar data have been published from Spanish GP doctors. In our sample, there was a disagreement between the prevalence of insomnia or anxiety and the consumption of BZDs [51, 52], which has also recently been observed in a study with a different health system model [53]. These data suggest that some health issue as insomnia or anxiety probably are not always coded in the informatic system by the GP doctors [54].

In some recent studies on the trend of BDZ prescriptions in Western countries, an increase in consumption has been observed [55, 56], while other studies have shown a stabilization or some decrease [34, 45, 57], depending on the characteristics of the population, legal aspects related to the prescription, and the period of follow-up.

When we analysed by the type of BZD used, we observed $66.9 \%$ consumption of short-intermediate half-life BZDs, in agreement with the results of a similar study conducted in the US [7]. Similarly, as observed in our study, approximately one quarter of the prescriptions of BZDs in adults were for long half-life BZDs. This proportion was consistent with a recent study of the use of BZDs among older adults in Quebec, where $24.3 \%$ of consumers received long half-life BZDs [58]. Long halflife BZDs may present risks in older people that are

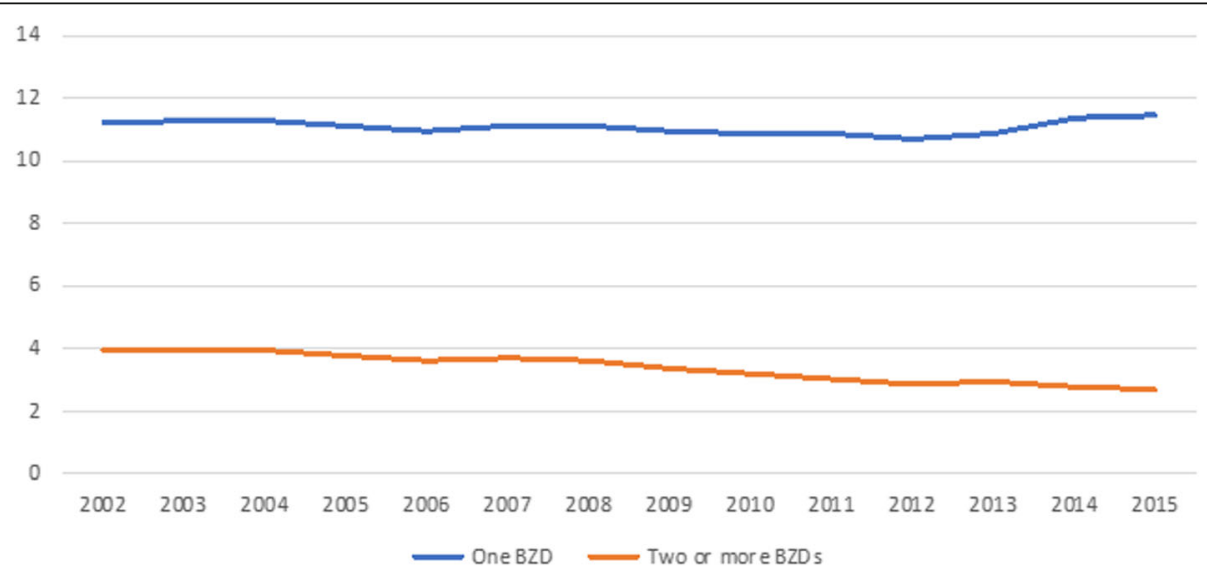

Fig. 3 Trend of percentage of patients who are taking two or more BZDs at the same time compared with those who are taking only one BZD from 2002 to 2015 
associated with the drug's long half-life [59], as well as age-related changes in the pharmacokinetic and pharmacodynamic profiles of these compounds [60].

In our study, BZD consumption trends according to half-life and sex showed an increased use of shortintermediate half-life BZDs from 2002 to 2015 in women (11.7\% vs. $13.4 \%)$, but use remained constant in men (6.1 vs. 6.1\%). Studies conducted in northern Europe $[61,62]$ suggested that these prescription differences by sex were due to clinical reasons. Mendelson et al. showed that men consumed more long half-life BZDs than women; these long half-life BZDs were mainly indicated for anxiety, with insomnia being the main indication for short half-life BZDs [63].

In our observation period of 14 years, a more important reduction was observed in the use of long half-life BZDs, while consumption of the short half-life BZDs remained stable. Benzodiazepines are relatively safe for short-term use ( 2 to 4 weeks), but their safety has not been established beyond that period, and dependence develops in approximately half of patients who use benzodiazepines for longer than 1 month [64]. Short-intermediate half-life BZDs are typically used as hypnotic agents (e.g., triazolam), and long half-life BZDs are used as anxiolytic or anticonvulsant agents (e.g., diazepam and clonazepam). There is modest evidence that benzodiazepines with a shorter half-life are associated with a greater risk of dependence [65]. Perhaps this greater risk of dependence effect could explain the fact that there was no reduction in their consumption during the observation period. Lorazepam and alprazolam, as described in similar studies in Spain, were the most commonly used active agents among the anxiolytics [66]. Lorazepam is indicated for the treatment of anxiety associated with depression, and alprazolam is an anxiolytic with antidepressant activity.

In Ireland, the average number of DDDs of the benzodiazepines prescriptions dispensed per year decreased during the study period, while the average number of DDDs of $\mathrm{Z}$ drugs prescriptions dispensed per year remained largely stable over time [57]. In one Norwegian study, as many as $18 \%$ of the BZD users were high dose users, which was defined as the use of $180 \mathrm{DDD} /$ year [67]. In a Danish study, the risk of exceeding a yearly dose of 180 DDD was highest among the oldest patients (eight-fold among patients older than 85 years) [68], similar to what we have observed in our study.

Despite the knowledge of most primary care physicians about the guidelines that warn against the use of long-term BZDs in the elderly population, few believe that this practice represents a serious clinical threat, and many do not feel prepared to address the problem with their patients [69]. Strategies aimed at implementing measures focused on clinical interventions that combine clinical education and drugs review [70] and re- evaluation of the benefits and risks associated with the use of BZDs can reduce their long-term prescription in primary care [71].

According to the data about $\mathrm{Z}$ drug prescription and comparisons to other population database studies, the observed prescribing rates for Z-drugs were lower than those in most recently published data from various countries across Europe [72-74], Asia [75] and the US [56]. It is difficult to make direct comparisons between the observed prescribing rates and those reported in other countries because of differences in the nature of the datasets, sample populations and time periods examined [76-78].

\section{Limitations}

This study had a series of limitations. First, the dispensing data from the Public Health System included the drugs that were obtained by the population under study, not the actual use of the drug. Second, there were no data available on the specific clinical indications or actual suitability of BZD use in our study population. Third, the actual consumption of these drugs could have been greater than that reflected in this study, since private dispensers were excluded and the denominator considered was the population census of the Health Region of Lleida, a population slightly larger than that obtaining drug under the Public Health System [52]. Finally, the estimation of consumption through the DDD value established by the WHO has additional limitations, since sometimes there may be differences between the DDD value established by the $\mathrm{WHO}$ and the actual dose used in clinical practice. However, this technical unit of measurement allows the comparison of consumption data between different countries. Finally, although the population included in the study was representative of the general population, it is not possible to ensure that the prescribing habits of family physicians were representative of the national prescribing habits of all general practitioners.

\section{Conclusions}

This study provides a description of trends regarding BZDs and Z-drugs use over a thirteen years period. The consumption of these drugs has been stable despite concerns about their safety and remains especially high in the elderly population, who are most sensitive to the possible side effects of these drugs. While consumption of long half-life BZDS and Z-drugs has decreased, the consumption of short half-life BZDs has remained stable. In addition, this study also shows a concerning tendency to co-consume these drugs. Given that there are treatment alternatives with fewer side effects for many of the indications for which these drugs are used, especially for the elderly, efforts should be made to better educate physicians and patients regarding these alternatives and reduce the inappropriate long-term use of BZDs and Z-drugs. 


\section{Abbreviations}

BZDs: Benzodiazepines; Z-drugs: Drugs related to benzodiazepines; ATC: Anatomical therapeutic classification; DDD: Defined daily dose; WHO: World Health Organization; ICD-9-CM: International Classification of Diseases, 10th revision (2016), Clinical Modification

\section{Acknowledgements}

Not applicable.

\section{Authors' contributions}

$F T$, JB, LG, MB, and GP, designed the study. FT and GP searched the literature. FT, LG and $\mathrm{MB}$ collected the data. JB and $\mathrm{FT}$ analysed the data. FT, $J B, F B$ and GP interpreted the data. FT, JB and GP wrote the manuscript draft. All authors revised the manuscript and approved it for submission. The authors read and approved the final manuscript.

\section{Funding}

Jordi de Batlle acknowledges the support from the Department of Health (PERIS 2016: SLT002/16/00364) and ISCIII (Miguel Servet 2019: CP19/00108); this work was co-funded by ERDF/ESF, "Investing in your future". Gerard Piñol-Ripoll acknowledges the support from the Department of Health (PERIS 2019 SLT008/18/00050).

\section{Availability of data and materials}

The datasets used and/or analysed during the current study are available from the corresponding author on reasonable request.

\section{Ethics approval and consent to participate}

This research project, with code P16/109, was approved by the reference ethics committee (Committee of Ethics and Clinical Research of Lleida (EIC).

\section{Consent for publication}

Not applicable.

\section{Competing interests}

Not applicable.

\section{Author details}

${ }^{1}$ Pharmacy Department, Clinical Neuroscience Research, IRBLleida, Arnau de Vilanova University Hospital, Lleida, Spain. ${ }^{2}$ Biomedical Research Networking Center in Respiratory Diseases (Centro de Investigación Biomédica en Red de Enfermedades Respiratorias, CIBERES), Madrid, Spain. ${ }^{3}$ Group of Translational Research in Respiratory Medicine, Arnau de Vilanova University Hospital and Santa Maria University Hospital, IRBLleida, Lleida, Spain. ${ }^{4}$ Pharmacy Department, Servei Català de la Salut (Catalan Health Services), Lleida, Spain. ${ }^{5}$ Unitat d'Avaluació Clínica (Clinical Evaluation Unit), Institut Català de la Salut (Catalan Institute of Health), Lleida, Spain. ${ }^{6}$ Unitat Trastorns Cognitius (Cognitive Disorders Unit), Clinical Neuroscience Research, IRBLleida, Santa Maria University Hospital, Rovira Roure $n^{\circ}$ 44, 25198 Lleida, Spain.

\section{Received: 14 October 2019 Accepted: 24 May 2020}

\section{Published online: 01 June 2020}

\section{References}

1. López-Muñoz F, Álamo C, García-García P. The discovery of chlordiazepoxide and the clinical introduction of benzodiazepines: half a century of anxiolytic drugs. J Anxiety Disord. 2011;25:554-62.

2. Sonnenberg CM, Bierman EJ, Deeg DJ, Comijs HC, van Tilburg W, Beekman AT. Ten-year trends in benzodiazepine use in the Dutch population. Soc Psychiatry Psychiatr Epidemiol. 2012;47:293-301.

3. Verger P, Mmadi Mrenda B, Cortaredona S, Tournier M, Verdoux H. Trajectory analysis of anxiolytic dispensing over 10 years among new users aged 50 and older. Acta Psychiatr Scand. 2018;137:328-41.

4. Brandt J, Alessi-Severini S, Singer A, Leong C. Novel measures of benzodiazepine and Z-drug utilisation trends in a Canadian provincial adult population (2001-2016). J Popul Ther Clin Pharmacol. 2019;26:e22-38.

5. Carrasco-Garrido P, Jimenez-Garcia R, Astasio-Arbiza P, Ortega-Molina P, de Miguel AG. Psychotropics use in the Spanish elderly: predictors and evolution between years 1993 and 2003. Pharmacoepidemiol Drug Saf. 2007;16:449-57.
6. Jackson G, Gerard C, Minko N, Parsotam N. Variation in benzodiazepine and antipsychotic use in people aged 65 years and over in New Zealand. N Z Med J. 2014;127:67-78

7. Olfson M, King M, Schoenbaum M. Benzodiazepine use in the United States. JAMA Psychiat. 2015;72:136-42.

8. Koyama A, Steinman M, Ensrud K, Hillier TA, Yaffe K. Ten-year trajectory of potentially inappropriate medications in very old women: importance of cognitive status. J Am Geriatr Soc. 2013;61:258-63.

9. Guina J, Merrill B. Benzodiazepines I: Upping the care on downers: the evidence of risk, benefits ans alternatives. J Clin Med. 2018;7(2):17.

10. American Geriatrics Society. Beers criteria update expert panel: American Geriatrics Society 2015 updated beers criteria for potentially inappropriate medication use in older adults. J Am Geriatr Soc. 2015;2015(63):2227-46.

11. MHRA. Benzodiazepines learning module. Prescribing points. [http://www. mhra.gov.uk/ConferencesLearningCentre/LearningCentre/ Medicineslearningmodules/Reducingmedicinerisk/ Benzodiazepineslearningmodule/CON234573] December 20, 2018.

12. Guerlais M, Grall-Bronnec M, Feuillet F, Gérardin M, Jolliet P, Victorri-Vigneau C. Dependence on prescription benzodiazepines and Z-drugs among young to middle-aged patients in France. Subst Use Misuse. 2015;50:320-7.

13. Gerlach LB, Strominger J, Kim HM, Maust DT. Discontinuation of chronic benzodiazepine use among adults in the United States. J Gen Intern Med. 2019:34:1833-40.

14. Mura T, Proust-Lima C, Akbaraly T, Amieva H, Tzourio C, Chevassus H, Picot MC, Jacqumin-Gadda $H$, Berr C. Chronic use of benzodiazepines and latent cognitive decline in the elderly: results from the three-city study. Eur Neuropsychopharmacol. 2013;23:212-23.

15. Park $H$, Satoh $H$, Miki A, et al. Medications associated with falls in older people: systematic review of publications from a recent 5-year period. Eur J Clin Pharmacol. 2015:71:1429-40.

16. Medicines and Healthcare products Regulatory Agency (MHRA). Addiction to benzodiazepines and codeine: supporting safer use. [http://www.mhra.gov.uk/ Safetyinformation/DrugSafetyUpdate/CON123123] Accessed 20 Dec 2018.

17. Weisberg RB, Dyck I, Culpepper L, Keller MB. Psychiatric treatment in primary care patients with anxiety disorders: a comparison of care received from primary care providers and psychiatrists. Am J Psychiatry. 2007;164:276-82.

18. Pek EA, Remfry A, Pendrith C, Fan-Lun C, Bhatia RS, Soong C. High prevalence of inappropriate benzodiazepine and sedative hypnotic prescriptions among hospitalized older adults. J Hosp Med. 2017;12:310-6.

19. Batty G, Hooper R, Oborne C, Jackson S. Investigating intervention strategies to increase the appropriate use of benzodiazepines in elderly medical inpatients. Br J Clin Gov. 2001;6:252-8.

20. Dionne P-A, Vasiliadis H-M, Latimer E, Berbiche D, Preville M. Economic impact of inappropriate benzodiazepine prescribing and related drug interactions among elderly persons. Psychiatr Serv. 2013;64:331-8.

21. Peterson JF, Kripalani S, Danciu I, Harrell D, Marvanova M, Mixon AS, et al. Electronic surveillance and pharmacist intervention for vulnerable older inpatients on high-risk medication regimens. J Am Geriatr Soc. 2014;62: 2148-52.

22. Fond G, Fajula C, Dassa D, Brunel L, Lancon C, Boyer L. Potentially inappropriate psychotropic prescription at discharge is associated with lower functioning in the elderly psychiatric inpatients. A cross-sectional study. Psychopharmacology. 2016;233:2549-58.

23. Johnson CF, Frei C, Downes N, McTaggart SA, Akram G. Benzodiazepine and z-hypnotic prescribing for older people in primary care: a cross-sectional population-based study. Brit J Gener Pract. 2016;66:e410-5.

24. Bourgeois J, Elseviers MM, Azermai M, Van Bortel L, Petrovic M, Vander Stichele RR. Benzodiazepine use in Belgian nursing homes: a closer look into indications and dosages. Eur J Clin Pharmacol. 2012;68:833-44.

25. Chen L, Bell JS, Visvanathan R, Hilmer SN, Emery T, Robson L, et al. The association between benzodiazepine use and sleep quality in residential aged care facilities: a cross-sectional study. BMC Geriatr. 2016;16:196.

26. Salkeld G, Cameron ID, Cumming RG, Easter S, Seymour J, Kurrle SE, et al. Quality of life related to fear of falling and hip fracture in older women: a time trade off study. BMJ. 2000;320:341-6.

27. Ng BJ, Le Couteur DG, Hilmer SN. Deprescribing benzodiazepines in older patients: impact of interventions targeting physicians, pharmacists, and patients. Drugs Aging. 2018;35:493-521.

28. Panneman MJ, Goettsch WG, Kramarz P, Herings RM. The costs of benzodiazepine-associated hospital-treated fall injuries in the EU: a Pharmo study. Drugs Aging. 2003;20:833-9. 
29. Schneeweiss S, Avorn J. A review of uses of health care utilization databases for epidemiologic research on therapeutics. J Clin Epidemiol. 2005;58:323-37.

30. Hallas J. Drug utilization statistics for individual-level pharmacy dispensing data. Pharmacoepidemiol Drug Saf. 2005;14:455-63.

31. Haukka J, Suvisaari J, Tuulio-Henriksson A, Lönnqvist J. High concordance between self-reported medication and official prescription database information. Eur J Clin Pharmacol. 2007;63:1069-74.

32. WHO Collaborating Centre for Drug Statistics Methodology, Norwegian Institute of Public Health. ATC/DDD Index 2018. [https://www.whocc.no/ atc_ddd_index/] Accessed 20 Dec 2018.

33. Agencia Española de Medicamentos y Productos Sanitarios [https://www. aemps.gob.es/] Accessed 20 Dec 2018.

34. Kurko T, Saastamoinen LK, Tuulio-Henriksson A, Taiminen T, Tiihonen J, Airaksinen M, Hietala J. Trends in the long-term use of benzodiazepine anxiolytics and hypnotics: a national register study for 2006 to 2014. Pharmacoepidemiol Drug Saf. 2018;27:674-82.

35. Caro-Mendivelso J, et al. Associations between socioeconomic index and mortality in rural and urban small geographic areas of Catalonia, Spain: Ecological study. J Epidemiol Res. 2015;2:80.

36. World Health Organization. Classification of Diseases, 10th Revision (ICD-10) [https://www.who.int/classifications/icd/en/] Accessed 20 Dec 2018.

37. Petitjean S, Ladewig D, Meier CR, Amrein R, Wiesbeck GA. Benzodiazepine prescribing to the Swiss adult population: results from a national survey of community pharmacies. Int Clin Psychopharmacol. 2007;22:292-8.

38. Lagnaoui R, Depont F, Fourrier A, et al. Patterns and correlates of benzodiazepine use in the French general population. Eur J Clin Pharmacol. 2004:60:523-9.

39. Linden M, Lecrubier $Y$, Bellantuono $C$, et al. The prescribing of psychotropic drugs by primary care physicians: an international collaborative study. J Clin Psychopharmacol. 1999;19:132-40.

40. Ohayon MM, Lader MH. Use of psychotropic medication in the general population of France, Germany, Italy, and the United Kingdom. J Clin Psychiatry. 2002;63:817-25.

41. Demyttenaere K, Bonnewyn A, Bruffaerts $R$, et al. Clinical factors influencing the prescription of antidepressants and benzodiazepines: results from the European study of the epidemiology of mental disorders (ESEMeD). J Affect Disord. 2008;110:84-93.

42. Van Hulter R, Leufkens HG, Bakker A. Usage patterns of benzodiazepines in a Dutch community: a 10 year follow-up. Pharm World Sci. 1998;20:78-82.

43. Ohayon MM, Caulet M, Priest RG, Guilleminault C. Psychotropic medication consumption patterns in the UK general population. J Clin Epidemiol. 1998; 51:273-83.

44. Kjosavik SR, Ruths S, Hunskaar S. Psychotropic drug use in the Norwegian general population in 2005: data from the Norwegian prescription database. Pharmacoepidemiol Drug Saf. 2009;18:572-8.

45. Brett J, Maust DT, Bouck Z, Ignacio RV, Mecredy G, Kerr EA, Bhatia S, Elshaug AG, Pearson SA. Benzodiazepine use in older adults in the United States, Ontario, and Australia from 2010 to 2016. J Am Geriatr Soc. 2018;66:1180-5.

46. Jorm AF, Grayson D, Creasey H, Waite L, Broe GA. Long-term benzodiazepine use by elderly people living in the community. Aust N Z J Public Health. 2000;24:7-10.

47. National Institute for Clinical Excellence. Guidance on the Use of Zaleplon, Zolpidem and Zopiclone for the Short-term Management of Insomnia. Technology Appraisal Guidance; 2004. p. 77.

48. Cook JM, Marshall R, Masci C, Coyne JC. Physicians' perspectives on prescribing benzodiazepines for older adults: a qualitative study. J Gen Intern Med. 2007;22:303-7.

49. Everitt $H$, McDermott L, Leydon G, Yules H, Baldwin D, Little P. GPs' management strategies for patients with insomnia: a survey and qualitative interview study. Br J Gen Pract. 2014;64:112-9.

50. Sivertsen $B$, Nordhus $1 H$, Bjorvatn $B$, Pallesen S. Sleep problems in general practice: a national survey of assessment and treatment routines of general practitioners in Norway. J Sleep Res. 2010;19:36-41.

51. Fourrier A, Letenneur L, Dartigues JF, Moore N, Bégaud B. Benzodiazepine use in an elderly community-dwelling population: characteristics of users and factors associated with subsequent use. Eur J Clin Pharmacol. 2001;57:419-25.

52. Simon GE, Ludman EJ. Outcome of new benzodiazepine prescriptions to older adults in primary care. Gen Hosp Psychiatry. 2006;28:374-8.

53. Albrecht JS, Wickwire EM, Vadlamani A, Scharf SM, Tom SE. Trends in insomnia diagnosis and treatment among Medicare beneficiaries, 20062013. Am J Geriatr Psychiatry. 2018;27:301-9.
54. Wolitzky-Taylor KB, Castriotta N, Lenze EJ, Stanley MA, Craske MG. Anxiety disorders in older adults: a comprehensive review. Depress Anxiety. 2010;27: 190-211.

55. Kaufmann CN, Spira AP, Depp CA, Mojtabai R. Long-term use of benzodiazepines and nonbenzodiazepine hypnotics, 1999-2014. Psychiatr Serv. 2018:69:235-8.

56. Kaufmann CN, Spira AP, Alexander GC, Rutkow L, Mojtabai R. Trends in prescribing of sedative-hypnotic medications in the USA: 1993-2010. Pharmacoepidemiol Drug Saf. 2016;25:637-45.

57. Cadogan CA, Ryan C, Cahir C, Bradley CP, Bennett K. Benzodiazepine and Zdrug prescribing in Ireland: analysis of national prescribing trends from 2005 to 2015. Br J Clin Pharmacol. 2018;84:1354-63.

58. Préville M, Bossé C, Vasiliadis HM, et al. Correlates of potentially inappropriate prescriptions of benzodiazepines among older adults: results from the ESA study. Can J Aging. 2012;31:313-22.

59. Hanlon JT, Schmader KE, Boult C, et al. Use of inappropriate prescription drugs by older people. J Am Geriatr Soc. 2002;50:26-34.

60. Madhusoodanan S, Bogunovic OJ. Safety of benzodiazepines in the geriatric population. Expert Opin Drug Saf. 2004;3:485-93.

61. Van der Waals FW, Mohrs J, Foets M. Sex differences among recipients of benzodiazepines in Dutch general practice. BMJ. 1993; 307:363-6.

62. Van der Heyden JHA, Gisle L, Hesse E, Demarest S, Drieskens S, Tafforeau J. Gender differences in the use of anxiolytics and antidepressants: a population based study. Pharmacoepidemiol Drug Saf. 2009;18:1101-10

63. Mendelson WB. Clinical distinctions between long-acting and short-acting benzodiazepines. J Clin Psychiatry. 1992;53(Suppl 12):4-7.

64. Lader M. Benzodiazepines revisited - will we ever learn? Addiction. 2011; 106:2086-109.

65. de las Cuevas C, Sanz E, de la Fuente J. Benzodiazepines: more "behavioural" addiction than dependence. Psychopharmacology. 2003;167: 297-303.

66. Vicente Sánchez MP, et al. Trends of Use of Anxiolytics and Hypnotics in Spain from 2000 to 2011. Rev Esp Salud Publica. 2013; 87:247-55.

67. Nordfjærn T. A population-based cohort study of anxiety, depression, sleep and alcohol outcomes among benzodiazepine and z-hypnotic users. Addict Behav. 2012;37:1151-7.

68. Holm E, Fosbol E, Pedersen $H$, Jensen TB, Nielsen M, Weeke $P$, et al. Benzodiazepine use in Denmark 1997-2008. Eur Geriatr Med. 2012;3: 299-303.

69. Cook JM, Biyanova T, Masci C, Coyne JC. Older patient perspectives on long-term anxiolytic benzodiazepine use and discontinuation: a qualitative study. J Gen Intern Med. 2007;22:1094-100.

70. Gould RL, Coulson MC, Patel N, Highton-Williamson E, Howard RJ. Interventions for reducing benzodiazepine use in older people: meta-analysis of randomised controlled trials. Br J Psychiatry. 2014; 204:98-107.

71. Mugunthan K, McGuire T, Glasziou P. Minimal interventions to decrease long-term use of benzodiazepines in primary care: a systematic review and meta-analysis. Br J Gen Pract. 2011;61:573-8.

72. Huerta C, Abbing-Karahagopian V, Requena G, Oliva B, Alvarez Y, Gardarsdottir $H$, et al. Exposure to benzodiazepines (anxiolytics, hypnotics and related drugs) in seven European electronic healthcare databases: a cross-national descriptive study from the PROTECT-EU project. Pharmacoepidemiol Drug Saf. 2016;25:56-65.

73. Sakshaug S, Handal M, Hjellvik V, Berg C, Ripel A, Gustavsen I, et al. Longterm use of Z-hypnotics and co-medication with benzodiazepines and opioids. Basic Clin Pharmacol Toxicol. 2017;120:292-8.

74. Cloos JM, Bocquet V, Rolland-Portal I, Koch P, Chouinard G. Hypnotics and triazolobenzodiazepines - best predictors of high-dose benzodiazepine use: results from the Luxembourg National Health Insurance Registry. Psychother Psychosom. 2015;84:273-83.

75. Takeshima N, Ogawa Y, Hayasaka Y, Furukawa TA. Continuation and discontinuation of benzodiazepine prescriptions: a cohort study based on a large claims database in Japan. Psychiatry Res. 2016;237:201-7.

76. Marra EM, Mazer-Amirshahi M, Brooks G, van den Anker J, May L, Pines JM. Benzodiazepine prescribing in older adults in U.S. ambulatory clinics and emergency departments (2001-10). J Am Geriatr Soc. 2015;63:2074-81. 
77. Benard-Laribiere A, Noize P, Pambrun E, Bazin F, Verdoux H, Tournier M, et al. Trends in incident use of benzodiazepines and Z-drugs in France from 2006 to 2012: a population-based study. Pharmacoepidemiol Drug Saf. 2017:26:162-6.

78. Alessi-Severini S, Bolton JM, Enns MW, Dahl M, Collins DM, Chateau D, et al. Use of benzodiazepines and related drugs in Manitoba: a population-based study. CMAJ Open. 2014;2:E208-16.

\section{Publisher's Note}

Springer Nature remains neutral with regard to jurisdictional claims in published maps and institutional affiliations.

Ready to submit your research? Choose BMC and benefit from:

- fast, convenient online submission

- thorough peer review by experienced researchers in your field

- rapid publication on acceptance

- support for research data, including large and complex data types

- gold Open Access which fosters wider collaboration and increased citations

- maximum visibility for your research: over $100 \mathrm{M}$ website views per year

At $\mathrm{BMC}$, research is always in progress.

Learn more biomedcentral.com/submissions 